and very seldom does Mr. Priestley reveal the result of their scientific work during the first winter : during the second, of course, little could be accomplished. But the interest of the volume lies in its being a full account of how six men lived through an antarctic winter practically on what land and sea produce, and so proved that this can be done with comparative safety. That is the importance of Mr. Priestley's book, and as such, it should be studied carefully by every future explorer in polar regions. The author has been careful to record every expedient and makeshift he and his comrades found useful in their long struggle against adverse circumstances, and it is all these trifling details that give great value only so; he often mulcts the public heavily for the privilege.

This is the conclusion forced upon the reader by a perusal of the Report of the Select Committee appointed to inquire into the question of the sale of patent and proprietary medicines. The anomalies and curiosities of the law and practice concerning these commodities are, the Committee finds, "numerous and remarkable," but as they are not specially pertinent to these columns, the interested reader is referred to the Report itself for examples.

The medicines in question differ widely in character. "At one end of the scale is the valuable scientific preparation; at the other is the mere

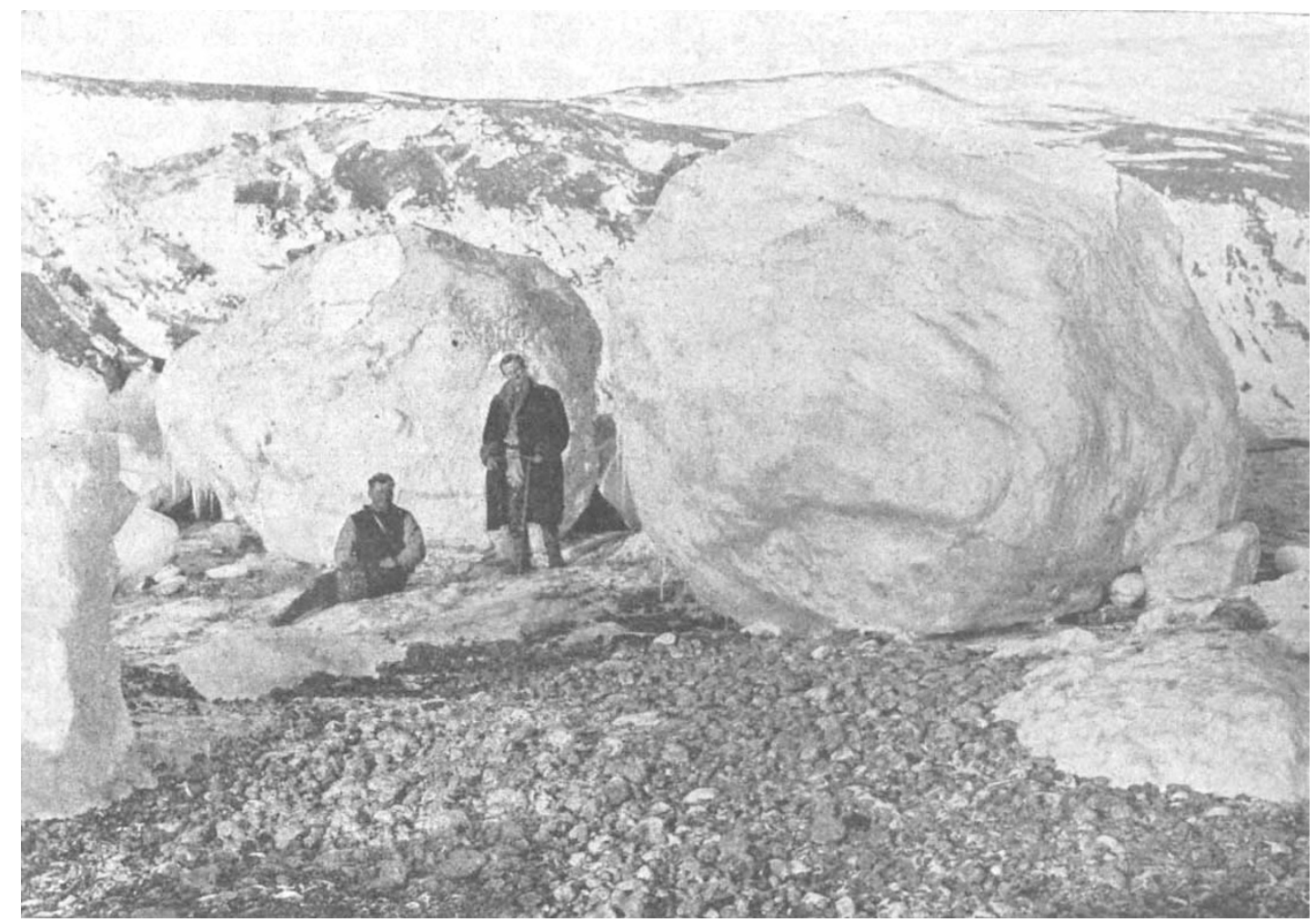

FIG. 2. - Ice boulders hurled up the beach by a heavy swell. From "Antarctic Adventure."

to the book. The work is well illustrated and contains three maps.

R. N. R. B.

\section{SECRET REMEDIES.}

I $T$ will scarcely be questioned that the freedom 1 allowed to quackery in this country is unreasonable. To estimate properly the effect of drugs on the progress of disease in the human body is one of the most difficult of tasks, even for highly trained observers; yet any person vending alleged remedies is permitted to assert the efficacy of his nostrums in the cure of ailments, and to use the public as corpus vile for them, practically without let or hindrance. Not NO. 2353, VOL. 94] vulgar swindle." They are classified by the Committee as follows:-

Class A: Non-Secret.-(I) Proprietary preparations consisting of genuine drugs, synthesised or extracted by skilled chemists and tested by therapeutists. Examples are aspirin, adrenaline, and urotropine. (2) Remedies which owe their value to skilful combination, such as mixtures of bismuth salts with pepsine. (3) Known drugs, with the formula disclosed; but mixed for convenience with inert substances the nature of which is a trade secret-e.g., "tabloids."

It is considered that, with some possible exceptions, there is nothing in this class which calls for interference in the public interest.

Class B: Secret.--(I) Simple household rem- 
edies, often originally manufactured from a doctor's family prescription, and undoubtedly beneficial for uncomplicated ailments. The chief criticism made upon the sale of medicines belonging to this group is that their retail price is out of all proportion to their cost, and that they are often recommended for cases they cannot benefit, thus causing the purchaser to run risk of serious injury by delay in seeking proper medical treatment. (2) Dangerous remedies which should not be sold at all, or only on a doctor's prescription; or which should not be sold for the purpose for which they are offered. (3) Fraudulent remedies: these are a large group, consisting of abortifacients, alleged cures for cancer, consumption, diabetes, paralysis, epilepsy, deafness, and so on, together with electric belts, apparatus for supplying oxygen to the system (otherwise than by respiration), "ionised" water, and the like. With a touch of humour, the Committee remarks that "the discovery of radium will probably add a number of remedies to this group." It has, in fact, already added some. The treatment of "remedies" included in this category need involve no doubt or hesitation. "They are, and are known by their makers to be, cruel frauds." The sale and advertisement of them should be prohibited under drastic penalties. Finally, (4) there is a large group of remedies making grossly exaggerated claims. In respect of these, it is regarded as beyond doubt that the public is defrauded on a large scale by promises which cannot be fulfilled.

A good deal was said during the inquiry about the difficulty, and even the impossibility, of completely analysing certain medicines-a matter which is vital to many proposals for dealing with secret remedies by law. It was pointed out that even such familiar and apparently simple articles as extracts of dandelion and gentian are really highly complex bodies, the exact composition of which is still unknown to chemistry, and when several such extracts are present in a mixture detection of all becomes difficult, and accurate determination of any may be out of the question. But whilst this is true enough, the focussing of the discussion upon this point puts the matter out of perspective. There are limits to the powers of analysis, but in a large majority of cases the essential nature of the principal constituents of any medicine can be detected with almost perfect certainty and determined with reasonable accuracy, given skill, time, and a sufficient quantity of material.

Several abuses in connection with secret remedies are indicated. Thus the composition has sometimes been changed whilst the name remained unaltered; e.g., acetanilide has been replaced by phenacetin, and the potent drug morphine has been added in one case, removed in another, without the change being brought to the purchaser's notice. Again, one medicine is recommended as "a safe and simple remedy" for both asthma and bronchial affections, though these are medically of quite different types, the former being NO. 2353, VOL. 94] a nervous disease; the latter an inflammation of the mucous membrane.

The Committee gives cogent reasons against adopting a suggestion made by medical witnesses and others, namely that every remedy sold should be compelled to bear a label stating its exact composition. This would inflict hardship; it would not necessarily convey useful information to the purchaser, who could not be expected to know chemical names such as, for example, "hexamethylene-tetramine"; moreover, an accurate statement might be in itself misleading. It is proposed, however, that an exact and complete statement of the ingredients and their proportions should be lodged with a department of the Government, and controlled by a confidential analysis. All patent, secret, and proprietary remedies should be registered with this department, and a special Court or Commission should have power to prohibit the sale or advertisement of such remedies, either in the public interest or on the ground of non-compliance with the law. New legislation is urgently needed to deal with a state of things which has become intolerable.

The findings and recommendations of the Committee are too lengthy to summarise further here. It may be said generally that the Report is fair but firm, and shows that its compilers, whilst considering legitimate interests, have not allowed themselves to be hoodwinked by the quack.

\section{ORGANISATION OF SCIENCE.}

UST before the beginning of the war much fruitful discussion was going on in the columns of NATURE, the Morning Post, and Science Progress on the subject of the encouragement of science; and those who are interested in the theme should read Dr. R. S. Woodward's address on the needs of research, delivered on the occasion of the dedication of the Marine Biological Laboratory, Woods Hole, Massachusetts (Science, August I4, 1914).

Dr. Woodward begins by exposing some of the popular fallacies regarding research-that it "is akin to necromancy" ; and that "the more remarkable results of research are produced not by the better balanced minds, but by aberrant types of mind popularly designated by that word of ghostly, if not ghastly, implications, namely, "genius." $\mathrm{He}$ has also exposed the absurdity that research institutions should busy themselves in soliciting suggestions from the amateur public outside, that is, "in casting drag-nets in the wide world of thought, or in dredging, as biologists would say, with the expectation that out of the vast slimy miscellanies thus collected there will be found by the aid of a corps of patient examiners some precious sediments of truth." $\mathrm{He}$ thinks that "important advances in knowledge are far more likely to issue from the expert than from the inexpert in research."

Dr. Woodward traverses the idea "that research is a harmless and a fruitless diversion in the business of education"; and gives some figures 